\title{
Vitamin D Deficiency Promotes Skeletal Muscle Hypersensitivity and Sensory Hyperinnervation
}

\author{
Sarah E. Tague, ${ }^{1,4}$ Gwenaëlle L. Clarke, ${ }^{1,4}$ Michelle K. Winter, ${ }^{2,4}$ Kenneth E. McCarson, ${ }^{2,4}$ Douglas E. Wright, ${ }^{3,4}$ \\ and Peter G. Smith ${ }^{1,4}$ \\ Departments of ${ }^{1}$ Molecular and Integrative Physiology, ${ }^{2}$ Pharmacology, Toxicology and Therapeutics, and ${ }^{3}$ Anatomy and Cell Biology, and ${ }^{4}$ Kansas \\ Intellectual and Developmental Disabilities Research Center, University of Kansas Medical Center, Kansas City, Kansas 66160
}

\begin{abstract}
Musculoskeletal pain affects nearly half of all adults, most of whom are vitamin D deficient. Previous findings demonstrated that putative nociceptors ("pain-sensing" nerves) express vitamin D receptors (VDRs), suggesting responsiveness to 1,25-dihydroxyvitamin D. In the present study, rats receiving vitamin D-deficient diets for 2- 4 weeks showed mechanical deep muscle hypersensitivity, but not cutaneous hypersensitivity. Muscle hypersensitivity was accompanied by balance deficits and occurred before onset of overt muscle or bone pathology. Hypersensitivity was not due to hypocalcemia and was actually accelerated by increased dietary calcium. Morphometry of skeletal muscle innervation showed increased numbers of presumptive nociceptor axons (peripherin-positive axons containing calcitonin gene-related peptide), without changes in sympathetic or skeletal muscle motor innervation. Similarly, there was no change in epidermal innervation. In culture, sensory neurons displayed enriched VDR expression in growth cones, and sprouting was regulated by VDR-mediated rapid response signaling pathways, while sympathetic outgrowth was not affected by different concentrations of 1,25dihydroxyvitamin D. These findings indicate that vitamin D deficiency can lead to selective alterations in target innervation, resulting in presumptive nociceptor hyperinnervation of skeletal muscle, which in turn is likely to contribute to muscular hypersensitivity and pain.
\end{abstract}

\section{Introduction}

Chronic musculoskeletal pain poses major social and economic burdens, given that approximately one-third of adolescents and one-half of adults suffer from this disorder (De Inocencio, 2004; Bergman, 2007). Up to $93 \%$ of those reporting nonspecific musculoskeletal pain are deficient in vitamin $\mathrm{D}$ (serum 25 -hydroxyvitamin $\mathrm{D}[25(\mathrm{OH}) \mathrm{D}]<20 \mathrm{ng} / \mathrm{ml}[50 \mathrm{nmol} / \mathrm{L}]$ ) (Plotnikoff and Quigley, 2003), suggesting that insufficient levels of this secosteroid may contribute to the etiology of musculoskeletal pain. There is evidence that dietary vitamin $D$ supplementation can relieve musculoskeletal pain (Gloth et al., 1991; Glerup and Eriksen, 1999; de Torrenté de la Jara et al., 2006), leading some to promote vitamin $\mathrm{D}$ as a complementary or alternative medicine for nonspecific muscle pain. Nonetheless, the role of vitamin $\mathrm{D}$ in musculoskeletal pain remains controversial, as conditions that encourage vitamin D deficiency (obesity, sedentary lifestyle, senescence, female and menopausal) also predispose

Received July 16, 2011; accepted July 27, 2011.

Author contributions: S.E.T., K.E.M., D.E.W., and P.G.S. designed research; S.E.T., G.L.C., and M.K.W. performed research; S.E.T. and P.G.S. analyzed data; S.E.T. wrote the paper.

Funding for this work was provided by NIH Grants NICHD R01HD049615, NCCAM R21AT006629, and NIA F31AG032943 with core support from NICHD P3OHD002528. The content does not necessarily represent the views of these agencies. We thank Dr. Anuradha Chakrabarty for technical guidance, Dr. Anthony Norman, University of California Riverside, for kindly providing JN, and Dr. H. Clarke Anderson for providing vitamin D-deficient rat tissue for experiments preliminary to this study. We thank the staff of the Kansas Intellectual and Developmental Disabilities Research Center for facilitating these studies, including Doug Brownyard for maintaining core behavioral equipment, Dr. Don Warn for microscopy and imaging assistance, and Jing Huang for histology services.

The authors declare no competing financial interests.

Correspondence should be addressed to Peter G. Smith, University of Kansas Medical Center, Institute for Neurological Disorders, 3901 Rainbow Boulevard, Kansas City, KS 66160. E-mail: psmith@kumc.edu.

DOI:10.1523/JNEUROSCI.3637-11.2011

Copyright $\odot 2011$ the authors $\quad 0270-6474 / 11 / 3113728-11 \$ 15.00 / 0$ individuals to musculoskeletal pain (Bergman, 2007; Yetley, 2008). This study uses a rodent model to investigate whether vitamin D deficiency causes deep tissue mechanical hypersensitivity and explores potential mechanisms.

Vitamin D affects many cell types through nuclear vitamin D receptors that regulate gene expression and cell membrane VDRs that mediate nongenomic rapid responses. VDRs are activated by the vitamin D hormone metabolite, 1,25-dihydroxyvitamin D $\left[1,25(\mathrm{OH})_{2} \mathrm{D}\right]$, which is converted from circulating $25(\mathrm{OH}) \mathrm{D}$. We recently found that unmyelinated, peptidergic neurons in rat dorsal root sensory ganglia (DRGs) express nuclear, membrane, and cytoplasmic VDRs and the enzyme that converts $25(\mathrm{OH}) \mathrm{D}$ to $\left(1,25(\mathrm{OH})_{2} \mathrm{D}\right)$, suggesting that these presumptive painsensing neurons produce and respond to active vitamin D metabolites (Tague and Smith, 2011).

We hypothesized that vitamin D deficiency contributes to muscle hypersensitivity through direct effects on sensory nociceptor neurons. Reduced vitamin D dietary intake can induce persistent vitamin D deficiency in laboratory rats (Weishaar and Simpson, 1987), and we used this model to assess cutaneous and deep muscle sensitivity. However, reductions in serum calcium that can accompany vitamin $\mathrm{D}$ deficiency can affect many physiological functions (Demay, 2006), and can be corrected by administering a diet high in calcium and phosphate (Weishaar and Simpson, 1987). In this study, vitamin D-deficient diets with normal and high calcium/phosphate content are used to isolate the direct versus indirect effects of vitamin D deficiency on deep tissue sensitivity in rats.

Our findings show that 4 weeks of a vitamin D-deficient diet produces muscle mechanical hypersensitivity and balance deficits. 
Instead of correcting this phenotype, increased dietary calcium accelerated its development. Concurrent with muscle hypersensitivity was skeletal muscle hyperinnervation by putative nociceptor axons. This appears to be due to direct actions of vitamin $\mathrm{D}$ metabolites on rapid response VDRs, as both $1,25(\mathrm{OH})_{2} \mathrm{D} 3$ and the rapid response specific agonist 6-s-cis-lumisterol (JN) regulated neurite outgrowth by peripherin-positive sensory neurons in culture. The greater density of "pain-sensing" nerves in muscles of vitamin D-deficient rats may therefore contribute to the observed hypersensitivity.

\section{Materials and Methods}

\section{Animals and diets}

Animal protocols and procedures were in accordance with NIH guidelines for the care and use of laboratory animals and approved by the University of Kansas Medical Center Animal Care and Use Committee. Fifteen weaned female Sprague Dawley rats (Harlan) housed 2-3/cage in forced-air-ventilated micro-isolation cages with a $14 \mathrm{~h}$ light/10 h dark cycle and fed ad libitum normal chow. At $31 \mathrm{~d}$ of age, rats were anesthetized with ketamine $70 \mathrm{mg} / \mathrm{kg}$ (Pfizer)/xylazine $6 \mathrm{mg} / \mathrm{kg}$ (i.p.) (Lloyd Laboratories) and ovariectomized via bilateral hindflank incisions. Upon waking and at 24 and $48 \mathrm{~h}$ after the operation, rats were administered ketoprofen $5 \mathrm{mg} / \mathrm{kg}$ (s.c.) (Ketofen; Fort Dodge Animal Health) as an analgesic. Ovariectomized rats were used to eliminate estrous cycle-driven variations in behavioral sensitivity (Craft, 2007) and sensory neuronal VDR expression (Tague and Smith, 2011); this model also incorporates risk factors seen in affected human populations with musculoskeletal pain (female, postmenopausal or estrogen suppressed) (Gaugris et al., 2005; Alexander et al., 2007; Khan et al., 2010). The effectiveness of the ovariectomy was assessed at the end of the experiment by confirming that all uteri were atrophic.

At $48 \mathrm{~d}$ of age, rats were randomly assigned to treatment groups and fed one of three diets: Control: $2.2 \mathrm{IU} / \mathrm{g}$ vitamin D (cholecalciferol), 0.47\% Ca, 0.3\% P (Harlan Teklad, TD.07370); VD-/+Ca: vitamin D-depleted, 2.5\% Ca, 1.5\% P (Harlan Teklad, TD.07541); VD-: vitamin D-depleted, $0.47 \%$ Ca, 0.3\% P (Harlan Teklad, TD.89123). The VD-/+Ca diet was based on previously published reports that increasing dietary $\mathrm{Ca}$ from $0.47 \%$ to $2.5 \%$ normalizes serum Ca in prolonged vitamin $D$ deficiency (1.5\% $\mathrm{P}$ is needed as a counterbalance) (Weishaar and Simpson, 1987). The identity of each diet was removed and replaced with a color code by an uninvolved technician to blind the investigators to the dietary treatments. Food was replaced twice weekly, and weighed before and after changing. Rats were maintained on their assigned diet for 4 weeks and weighed weekly. After 2 weeks, $1-2 \mathrm{ml}$ of blood was drawn from the tail vein. Serum was collected and stored at $-20^{\circ} \mathrm{C}$. At the end of the study, rats were deeply anesthetized with ketamine $70 \mathrm{mg} / \mathrm{kg} /$ xylazine $6 \mathrm{mg} / \mathrm{kg}$ (i.p.), thoracic cavities were opened, blood was removed for serum analysis via cardiac puncture, and the rats were perfused with $50 \mathrm{ml}$ of cold $0.9 \%$ saline containing $10 \mathrm{U} / \mathrm{ml}$ heparin (APP Pharmaceuticals) at a rate of $40 \mathrm{ml} / \mathrm{min}$, followed by $150-200 \mathrm{ml}$ of $4 \%$ formaldehyde, prepared in PBS from paraformaldehyde (Sigma-Aldrich).

\section{Behavioral testing}

All behavioral testing was performed in a quiet room under normal fluorescent lighting $6-8 \mathrm{~h}$ into the light cycle. The rat cages were moved to the behavior room $1 \mathrm{~h}$ before testing.

Muscle mechanical sensitivity. Humans with vitamin D deficiency exhibit muscle pain in muscles at multiple locations. However, the strongest association between vitamin $\mathrm{D}$ deficiency and pain is reported to occur in leg muscles (Heidari et al., 2010). Accordingly, we assessed sensitivity in hindlimb musculature. The muscle compression test we used is similar to one previously described (Skyba et al., 2005; Sharma et al., 2009). A digital Randall-Selitto instrument (IITC Life Science) with a plastic cap that has a $0.5-\mathrm{cm}$-wide surface area was used. During the week before diet manipulation, rats were habituated to rat slings (IITC Life Science) for $5 \mathrm{~min}$ on 2 separate days. One day before starting diets and each week thereafter, rats were stabilized in slings to allow free access to their hindlimbs. While holding the left hindpaw, the flat side of the probe was placed against the left inner calf and the pressure sensor was placed on the center of the exterior calf muscle. The instrument was slowly compressed until the rat attempted a limb withdrawal. In two instances occurring in different treatment groups, rats vocalized instead of withdrawing; compression was stopped to avoid tissue damage and force was recorded. These values were similar to those of other rats within the same group and were included in analysis. The calf was compressed three times and the maximum force applied was recorded and averaged. The left calf was shaved each week $3 \mathrm{~d}$ before muscle compression under brief isoflurane anesthesia. In a pilot study, we found that $2.5 \%$ lidocaine $/ 2.5 \%$ prilocaine cream (TOLMAR) applied to the calf skin of control rats for 30 min prevented a withdrawal response to pinprick, but did not affect withdrawal responses to muscle compression $(360 \pm 65 \mathrm{~g}$ pretreatment vs $329 \pm 43 \mathrm{~g}$ after treatment). This is consistent with previous findings (Skyba et al., 2005) and supports the idea that the cutaneous contribution to the compression withdrawal response is minimal. Muscle compression was analyzed before and after cutaneous anesthesia at week 4 .

Cutaneous mechanical sensitivity. Cutaneous mechanical sensation was measured using methods similar to those previously described (Christianson et al., 2007). Rats were allowed to habituate for $20 \mathrm{~min}$ on a wire-mesh grid with Plexiglas dividers. A 4 g monofilament was applied to the center of the plantar surface five times per trial for a total of three trials. The number of positive responses was recorded, and the percentage withdrawal response for each paw was calculated. A response was considered positive when the rat retracted its hindpaw in response to the monofilament. The results shown are averages from the left and right hindpaws. Cutaneous sensitivity was measured $2 \mathrm{~d}$ before dietary manipulation and each week thereafter. In addition, we measured withdrawal threshold in all groups at week 4 using an electronic von Frey anesthesiometer (IITC Life Science). The results presented are averages from three trials on each foot.

Balance. Balance was assessed using methods similar to those previously described (Muller et al., 2008). An elevated, 2.5-cm-diameter round dowel was suspended between two support stands with an enclosed plastic platform at one end. At the ages of 28, 39, and $41 \mathrm{~d}$, rats were trained by placing them on the beam at increasing distances from the platform box until they voluntarily walked the full $110 \mathrm{~cm}$ of the beam. Two days before starting the diets and at weeks 2 and 4, rats were videotaped for three beam walk trials. The videos were analyzed to determine the number of hindpaw footfall slips (faults) per beam walk, which were then averaged.

Muscle strength. Grip strength was measured using methods previously described (Smittkamp et al., 2010). Three days before starting diets and at weeks 2 and 4, rats were placed on a wire grid attached to a digital force gauge (San Diego Instruments). The maximum grip force applied by the forelimbs was measured as the rats were gently pulled until their grip was broken. This was repeated three times for each rat and the maximum force was recorded.

General locomotor activity. Rats were placed in a Force Plate Actimeter (BASi) (Fowler et al., 2001) and allowed to move freely for $5 \mathrm{~min}$. Movements were detected by force transducers and recorded by a computer, and rearing events were recorded by the investigator.

\section{Serum measurements}

Serum 25-hydroxyvitamin D was measured by direct ELISA (Immunodiagnostik) according to manufacturer instructions. Serum calcium and phosphorous were measured by an outside laboratory (Physicians Reference Laboratory) by spectrophotometry.

\section{Tissue processing}

The left calf muscles (gastrocnemius and soleus) were postfixed in Zamboni's fixative overnight at $4^{\circ} \mathrm{C}$. Weight and volume (determined by fluid displacement in a graduated cylinder) were recorded. The muscles were washed and cryoprotected at $4^{\circ} \mathrm{C}$ in PBS with $30 \%$ sucrose for 2 weeks. The entire calf was cut in the transverse plane at $25 \%, 50 \%$, and $75 \%$ of the way through the muscle. The muscle pieces were embedded in tissue freezing media (Electron Microscopy Science), frozen in liquid nitrogencooled isopentane, and stored at $-80^{\circ} \mathrm{C}$. Thawed $20 \mu \mathrm{m}$ cryosections were stained with hematoxylin and eosin (H\&E).

The left tibia was postfixed in Zamboni's fixative overnight at $4^{\circ} \mathrm{C}$. The bones were washed at $4^{\circ} \mathrm{C}$ in PBS changed daily for $3 \mathrm{~d}$, then decalcified in PBS containing $10 \%$ EDTA, pH 7.4, for 2 weeks at $4^{\circ} \mathrm{C}$. The decalcified 
bones were cryoprotected overnight at $4^{\circ} \mathrm{C}$ in $30 \%$ sucrose. The bone was cut in half along the transverse plane. The proximal portion was cut in half along the sagittal plane and the medial portion was embedded in tissue freezing media for sectioning of the epiphyseal plate at $20 \mu \mathrm{m}$. The distal half of the bone was embedded in tissue freezing media for transverse sections of the diaphysis. Bones were frozen on dry ice, stored at $-80^{\circ} \mathrm{C}$, and sections were stained with $\mathrm{H} \& \mathrm{E}$.

The right footpad was removed with a scalpel after saline perfusion and before perfusion with Zamboni's fixative. Footpads were fixed in Zamboni's fixative for $1.5 \mathrm{~h}$ at room temperature, washed, and cryoprotected at $4^{\circ} \mathrm{C}$ in $30 \%$ sucrose changed daily for 1 week. Footpads were bisected along the sagittal axis, embedded in tissue freezing media, frozen on dry ice, and stored at $-80^{\circ} \mathrm{C}$.

\section{Immunostaining of nerve fibers in footpads and muscle}

Thawed sections were preincubated in $1.5 \%$ donkey serum (Jackson ImmunoResearch Laboratories), 0.5\% gelatin (Sigma-Aldrich), and 0.5\% Triton X-100 (Sigma-Aldrich) prepared in Superblock (Thermo Scientific) for $1 \mathrm{~h}$ at room temperature, incubated overnight at room temperature in primary antibodies diluted in incubation solution $(50 \%$ preincubation solution, 50\% Superblock), and for $2 \mathrm{~h}$ with secondary antibodies. Slides were washed in PBS containing 0.25\% Triton X-100 before and after the secondary antibody application. Primary and secondary antibodies were diluted as follows: 1:500 chicken anti-peripherin (Millipore Bioscience Research Reagents) (Tague and Smith, 2011), 1:200 sheep anti-calcitonin gene-related peptide (CGRP, Biomol) (Ruscheweyh et al., 2007; Tague and Smith, 2011), 1:1000 rabbit antivesicular monoamine transporter 2 (VMAT2, Millipore Bioscience Research Reagents) (Witkovsky et al., 2004), 1:1500 rabbit antiNeurofilament H (NFH, Sigma) (Besalduch et al., 2011), 1:1200 rabbit anti-protein gene product 9.5 (PGP 9.5 Serotec) (Chakrabarty et al., 2011), 1:1500 donkey anti-chicken DyLight 488 (Jackson ImmunoResearch Laboratories), 1:750 donkey anti-sheep Dylight 649 (Jackson ImmunoResearch Laboratories), 1:1000 donkey anti-rabbit Alexa 647 (Invitrogen), or 1:200 donkey anti-rabbit Cy2 (Jackson ImmunoResearch Laboratories). $\alpha$-Bungarotoxin Alexa Fluor 488 (Invitrogen) was applied during secondary incubation. All primary antibodies have been previously characterized as indicated. In addition, primary omission controls were performed.

\section{Quantitation of innervation density}

Innervation density was determined in deidentified, randomly sorted samples. Subject identity was revealed only at the completion of quantification. Nerve fibers included in analysis had signal intensities that were at least fourfold above background tissue fluorescence.

Muscle. Images were obtained from transverse sections of the left lateral gastrocnemius muscle, which is located on the outside of the calf where the pressure sensor was applied during muscle compressions. A total of 18 images were taken per animal, six each from three levels at $25 \%, 50 \%$, and $75 \%$ through the proximodistal extent of the muscle. A stereological grid was superimposed over the images, and numbers of grid intersections overlying immunofluorescently labeled axons/neuromuscular junctions were counted and divided by the total number of tissue intersections to provide the apparent percentage area occupied by nerves/neuromuscular junctions (Clarke et al., 2010). Each image had a total field area of $1.3 \mathrm{~mm}^{2}$, and each grid square area was $1720 \mu \mathrm{m}^{2}$.

Footpads. Three images were taken by a blinded observer from each of two sagittal sections $\sim 100 \mu \mathrm{m}$ on either side of the midline, which corresponds to roughly the same region used for cutaneous mechanical sensitivity testing. Intra-epidermal nerve fiber density (IENF) was determined by counting the number of immunofluorescently labeled nerves crossing the dermal-epidermal junction per millimeter, excluding fragments not crossing the dermal-epidermal junction (Lauria et al., 2005). To obtain total epidermal nerve fiber density, a stereological grid was superimposed over the images, and numbers of grid intersections overlying immunofluorescently labeled axons were counted and divided by the total number of epidermal intersections (excluding the keratinized layer, which is not innervated), to provide the apparent percentage of epidermal area occupied by nerves (Clarke et al., 2010). Each image had a total field area of $0.3 \mathrm{~mm}^{2}$, and each grid square area was $112.5 \mu \mathrm{m}^{2}$.

\section{Bone measurements}

Bone sections $(20 \mu \mathrm{m})$ were stained with hematoxylin and eosin and analyzed. For growth plate analysis, height and cell number of three fully visible chondrocyte columns in the center of each section were measured and averaged. Bone circumference and bone marrow area were measured in transverse sections of the diaphysis.

\section{Primary neuronal cell cultures}

Sensory. DRGs were removed from 6-week-old female Sprague Dawley rats, dissociated with $2 \mathrm{U} / \mathrm{ml}$ dispase (ICN Biomedicals) and $2 \mathrm{mg} / \mathrm{ml}$ collagenase type 1A (Sigma) and plated on glass coverslips (Bellco) coated with poly-D-lysine (Sigma) and laminin (Invitrogen) in 24-well culture dishes. Cultures were maintained for $4 \mathrm{~d}$ in Neurobasal A media (Invitrogen) containing $0.5 \mathrm{~mm}$ glutamine (Sigma), 2\% B27 (Invitrogen), $100 \mu \mathrm{g} / \mathrm{ml}$ Primocin (InvivoGen), $20 \mu \mathrm{M}$ FrdU (Sigma) and $20 \mu \mathrm{M}$ uridine (Sigma), with concentrations of $1,25(\mathrm{OH})_{2} \mathrm{D} 3$ or JN that ranged from 0 to $100 \mathrm{pm}$. Cultures were incubated at $37^{\circ} \mathrm{C}$ with $5 \% \mathrm{CO}_{2}$ and media was changed after 24 and $72 \mathrm{~h}$. Cells were fixed in $4 \%$ formaldehyde for $1 \mathrm{~h}$, DAPI stained, and immunostained for peripherin (chicken 1:1000, Millipore Bioscience Research Reagents) (Tague and Smith, 2011), NFH (mouse 1:200, Sigma) (Herde et al., 2010), or VDR (rabbit 1:25, GeneTex) (Tague and Smith, 2011), peripherin, and growthassociated protein 43 (GAP43) (mouse 1:240, Zymed) (Watanabe et al., 2009). Culture studies were conducted in triplicate and repeated twice.

Sympathetic. Superior cervical ganglia were removed from 1-d-old rats, dissociated with $0.25 \%$ trypsin-EDTA (Invitrogen) and collagenase 1A (Sigma), and plated on poly-D-lysine and laminin-coated coverslips (Clarke et al., 2010). Cultures were maintained in Neurobasal A media as described above with the addition of $10 \mu \mathrm{g} / \mathrm{ml} \mathrm{NGF}$ (Alomone Labs) for $48 \mathrm{~h}$, with 0 , 20, or $100 \mathrm{pm} 1,25(\mathrm{OH})_{2} \mathrm{D} 3$. Cultures were fixed in $4 \%$ formaldehyde, DAPI stained, and immunofluorescently labeled for peripherin and VDR. Cultures were grown in triplicate and repeated twice.

\section{Neurite area quantitation}

A stereological grid was superimposed over culture images, and numbers of grid intersections crossing an immunostained nerve fiber were counted and divided by the total number of intersections within each field to provide neurite area; this was divided by the number of viable neurons per field, determined by DAPI staining, to provide an estimate of neurite area per neuron (Chakrabarty et al., 2008). Each image had a total field area of $0.15 \mathrm{~mm}^{2}$, and each grid square area was $222.8 \mu \mathrm{m}^{2}$.

\section{Statistical analysis}

All values are expressed as mean \pm SEM. One-way ANOVA was used to analyze results when comparing multiple treatments at a single time point. When comparing effects on animals over multiple time points with multiple treatments, two-way repeated-measures ANOVA was used. When data failed either the Shapiro-Wilk normality $(p<0.05)$ or Levene median equal variance $(p<0.05)$ tests, ANOVAs were conducted using the Kruskal-Wallis test for one-way ANOVA or Conover test for two-way ANOVA. Post hoc multiple comparisons were completed using the Student-Newman-Keuls method. For all tests, $n$ equals 5 for each treatment group, except the cultures, where $n$ equals 6 for each treatment group, and statistical significance was accepted at $p \leq 0.05$.

\section{Results}

\section{A rat model of Vitamin D deficiency}

Vitamin D deficiency in people occurs as a result of insufficient sunlight exposure and dietary limitations. In the laboratory rat, diet is the primary source of vitamin $\mathrm{D}$ and a diet depleted of vitamin $\mathrm{D}$ produces conditions that resemble deficiencies in humans. Groups of Sprague Dawley rats were fed one of three diets: Control: normal vitamin D, calcium, and phosphate; VD-/+Ca: vitamin D-depleted, elevated calcium and phosphorus; or VD-: vitamin $\mathrm{D}$-depleted, normal calcium and phosphorus (Table 1). Rats fed vitamin $\mathrm{D}$-deficient diets showed weight gains comparable to control subjects over the 4 week study (Table 1). However, food consumption was increased in the $\mathrm{VD}-/+\mathrm{Ca}$ group 
Table 1. Diet, weight, and serum analysis

\begin{tabular}{|c|c|c|c|c|c|c|c|c|c|c|c|c|}
\hline & \multicolumn{3}{|l|}{ Diet } & \multicolumn{2}{|l|}{ Food intake } & \multicolumn{3}{|l|}{ Weight } & \multicolumn{2}{|c|}{ Serum 25(OH)D } & \multirow{2}{*}{$\begin{array}{l}\text { Serum Ca } \\
\text { Week } 4 \\
(\mathrm{mg} / \mathrm{dl})\end{array}$} & \multirow{2}{*}{$\begin{array}{l}\text { Serum P } \\
\text { Week } 4 \\
(\mathrm{mg} / \mathrm{dl})\end{array}$} \\
\hline & $\begin{array}{l}\text { Vitamin D3 } \\
(\mathrm{IU} / \mathrm{g})\end{array}$ & $\mathrm{Ca}(\%)$ & $P(\%)$ & $\begin{array}{l}\text { Week } 2 \\
\text { (kcal/d) }\end{array}$ & $\begin{array}{l}\text { Week } 4 \\
\text { (kcal/d) }\end{array}$ & $\begin{array}{l}\text { Week } 0 \\
\text { (g) }\end{array}$ & $\begin{array}{l}\text { Week } 2 \\
\text { (g) }\end{array}$ & Week 4 (g) & $\begin{array}{l}\text { Week 2 } \\
\text { (nmol/L) }\end{array}$ & $\begin{array}{l}\text { Week } 4 \\
(\mathrm{nmol} / \mathrm{L})\end{array}$ & & \\
\hline cominor & 2.2 & 0.47 & 0.3 & $58.9 \pm 0.4$ & $63.7 \pm 0.1$ & $164 \pm 4$ & $224 \pm 5$ & $264 \pm 5$ & $51.8 \pm 6.0$ & $70.8 \pm 6.3$ & $11.0 \pm 0.1$ & $8.5 \pm 0.4$ \\
\hline VD- & - & 0.47 & 0.3 & $59.9 \pm 0.3$ & $66.4 \pm 0.6^{*}$ & $166 \pm 3$ & $224 \pm 2$ & $260 \pm 5$ & $18.3 \pm 2.5^{*}$ & $4.2 \pm 1.5^{*}$ & $11.0 \pm 0.1$ & $8.8 \pm 0.4$ \\
\hline
\end{tabular}

${ }^{*} p<0.05$ compared to control. Values shown are means \pm SEM.

(week $2 p=0.002$, week $4 p=0.028$ ) and in the VD- group at week $4(p=0.014)$ compared to controls (Table 1). Serum $25(\mathrm{OH}) \mathrm{D}$ concentrations in both $\mathrm{VD}-/+\mathrm{Ca}$ and $\mathrm{VD}-$ rats were reduced below $25 \mathrm{nmol} / \mathrm{L}$ by week 2 and below $10 \mathrm{nmol} / \mathrm{L}$ by week 4 (Table $1, p<0.001$ for both groups at weeks 2 and 4 compared to control). Serum $\mathrm{Ca}$ and $\mathrm{P}$ levels at week 4 were not reduced, even though $\mathrm{Ca}$ is reported to be decreased with longer duration of vitamin D deficiency (Weishaar and Simpson, 1987). Therefore, dietary vitamin $\mathrm{D}$ restriction in rats produced a selective deficiency in serum 25-hydroxyvitamin D levels, similar to that seen in humans.

\section{Vitamin D-deficient rats show skeletal muscle hypersensitivity}

To determine whether increased muscle sensitivity reported in vitamin D-deficient humans also occurs in our rodent model, we assessed behavioral responses to calf muscle compression using a modified Randall-Selitto testing device. In control rats, force required to elicit a withdrawal response increased between 0 and 2 weeks, consistent with increasing body mass (Table 1), and plateaued thereafter (Fig. $1 A$ ). In VD- rats, mechanical sensitivity was normal through week 2 , but was increased by week 4 ( $p=$ 0.022 , Fig. $1 A$ ). Rats receiving the vitamin $\mathrm{D}$-deficient diet with elevated Ca showed normal sensitivity at week 1 , but were markedly hypersensitive at week 2 and thereafter (Fig. $1 A$; week 2: $p=0.022$, $\mathrm{VD}-/+\mathrm{Ca}$ vs control; $p=0.043, \mathrm{VD}-/+\mathrm{Ca}$ vs $\mathrm{VD}-$; week $3: p=$ 0.049 , VD -+ Ca vs control; week $4: p=0.04$, VD-/+Ca vs control). Thus, the high-calcium diet not only failed to reverse the hyperalgesic phenotype, but actually accelerated the onset of deep tissue mechanical hypersensitivity. Application of topical anesthetic cream at week 4 did not affect withdrawal threshold in vitamin D-deficient rats $(262 \pm 29 \mathrm{~g}$ vs $292 \pm 18 \mathrm{~g}$ for VD-/ $+\mathrm{Ca} ; 266 \pm 18 \mathrm{~g}$ vs $277 \pm 22 \mathrm{~g}$ for $\mathrm{VD}-$ ).

\section{Vitamin D deficiency does not alter cutaneous sensitivity}

We asked whether vitamin D deficiency leads to generalized hypersensitivity. Accordingly, we evaluated mechanical sensitivity of the hindpaw plantar cutaneous surface using a calibrated monofilament throughout the study. There were no differences between groups in mechanical withdrawal responses at any time (Fig. $1 B$ ). We further assessed cutaneous sensitivity by determining withdrawal threshold at week 4 by using an electronic von Frey anesthesiometer. There were no significant differences between groups (Control, $60 \pm 4 \mathrm{~g}$; VD-/+Ca, $51 \pm 3 \mathrm{~g}$; VD-, $57 \pm 5 \mathrm{~g}$ ). Therefore, vitamin $\mathrm{D}$ deficiency does not result in generalized changes in sensory thresholds, as evidenced by the lack of changes in cutaneous mechanical withdrawal thresholds.

\section{Balance is impaired in Vitamin D deficiency}

Falls occur more frequently in vitamin D-deficient individuals (Annweiler et al., 2010), suggesting that balance may be impaired. We assessed balance in vitamin D-deficient rats using a beam-walk test where numbers of foot slips were measured from
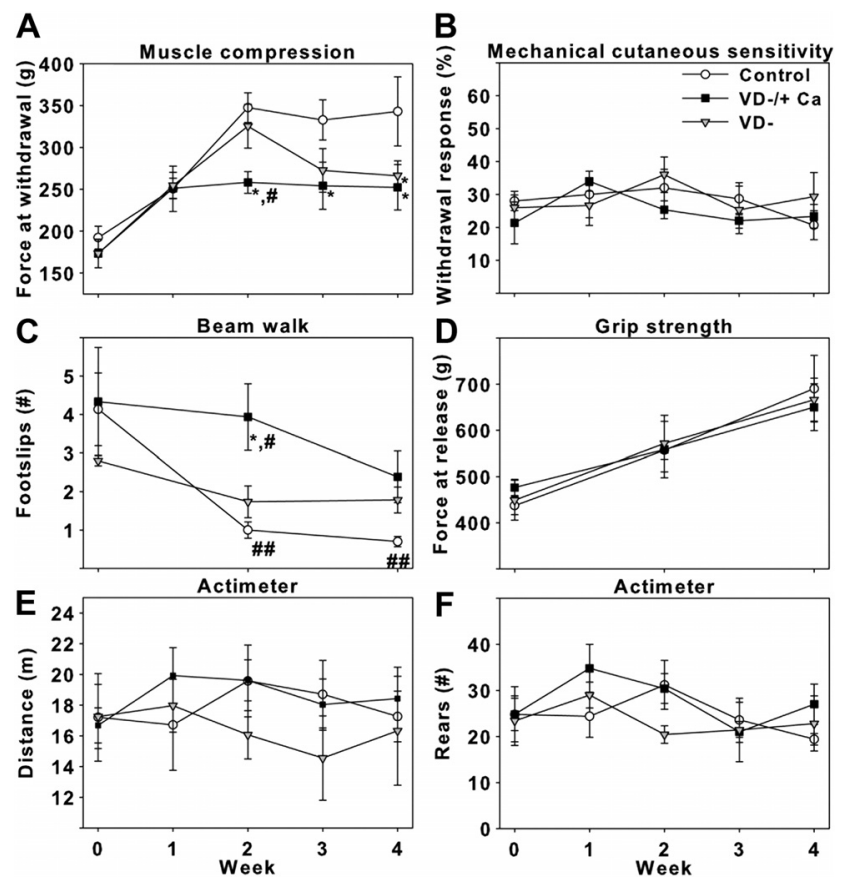

Figure 1. Behavioral comparisons of control (O), VD-I+Ca ( $\square)$, and VD- ( $)$ ) rats. $\boldsymbol{A}$, Changes in deep tissue pressure sensitivity, measured as the maximum force $(\mathrm{g})$ required to elicit an attempted limb withdrawal or vocalization to mechanical compression of the calf muscle. $\boldsymbol{B}$, There were no changes in cutaneous mechanical sensitivity as measured by the percentage of withdrawal responses to the application of a $4 \mathrm{~g}$ monofilament to the plantar surface of the hindpaw. $C$, Changes in balance were measured by the number of hindpaw slips while traversing an elevated 2.5 -cm-diameter, $110-\mathrm{cm}$-long beam. VD - and VD - / + Ca rats failed to improve, while control rats improved compared to initial performance. $\boldsymbol{D}$, There were no changes in forelimb grip strength, as measured by the force $(\mathrm{g})$ required to break the rats grip. $\boldsymbol{E}, \boldsymbol{F}$, Assessment of locomotor activity during a $5 \mathrm{~min}$ recording using a force-plate actimeter revealed no changes in distance traveled $(\boldsymbol{E})$ or number of rearing events $(\boldsymbol{F})$. $^{*} p<0.05$ compared to control in same week, ${ }^{\#} p<0.05$ compared to VD - in same week, ${ }^{\# \#} p<0.5$ compared to week 0 within the same group.

video recordings. Performance improved between 0 and 2 weeks in rats receiving a normal diet, and slips remained low at 4 weeks (Fig. $1 C ; p \leq 0.001$ for week 0 vs week 2 and week 4). Rats receiving the $\mathrm{VD}-$ diet, however, failed to improve throughout the study. Rats receiving the $\mathrm{VD}-1+\mathrm{Ca}$ diet performed worse than controls at weeks 2 and $4(p=0.002$ and 0.024 , respectively) and worse than VD- at week $2(p=0.017)$. Because vitamin $\mathrm{D}$-deficient rats tended to sit lower on the beam, use more caution, and make more balance corrections, the balance deficit may be greater than our assessments indicate.

\section{Vitamin D deficiency does not impair mobility or muscle strength}

Many factors could contribute to impaired beam-walk performance in vitamin D-deficient rats, including myopathic changes known to occur in protracted vitamin D deficiency (Schott and 
Wills, 1976). To assess whether overt muscle dysfunction occurs in our model of vitamin D deficiency, we measured grip strength (Fig. 1D). Forelimb grip strength increased with age in all groups, and vitamin D-deficient rats showed no deficits relative to rats on control diet, consistent with maintenance of normal muscle function. To determine whether the apparent balance deficits were associated with diminished mobility, the pattern of exploratory locomotor activity of each rat was analyzed in a force-plate actimeter. There were no significant differences in the overall activity between treatment groups, including total distance traveled (Fig. 1E) and number of rearing events (Fig. $1 F$ ). Thus, the balance deficits observed in our vitamin D-deficient rats do not appear to result from grossly impaired locomotor mobility or overt muscle weakness.

\section{Deep tissue hypersensitivity occurs in the absence of gross muscle atrophy or bone pathology}

Because vitamin D deficiency and deep muscle hypersensitivity are well established at 4 weeks after initiating vitamin D-deficient diets, we examined tissues at this time. Calf muscle volume (see Fig. $3 A$ ) and weight (data not shown) were essentially identical in all groups, and there were no discernible histological differences in muscle sections between groups (Fig. $2 A-C$ ), corroborating measurements of muscle strength and confirming an absence of muscle atrophy. It has been suggested that musculoskeletal pain in vitamin $\mathrm{D}$ deficiency derives from an expanding uncalcified bone matrix exerting pressure on the richly innervated periosteum (Mascarenhas and Mobarhan, 2004). In fact, shortened and bent tibia with enlarged and disorganized epiphyseal growth plates reportedly occur with prolonged vitamin D deficiency even when serum calcium is normal (Lester et al., 1982). We therefore examined tibiae from our vitamin D-deficient rats and found no overt abnormalities or differences in size or shape relative to controls. Histological analyses of decalcified tibial sections also showed organized growth plates with no expansion, either in height or number of chondrocytes per cartilage column (Table 2, Fig. 2D-F). Similarly, we did not observe changes in diaphysis circumference or marrow area (Table 2). These findings comport with prior observations that musculoskeletal pain in vitamin $\mathrm{D}$ deficiency occurs before bone pathology (Masood et al., 1989) and suggest that gross changes in muscle or bone integrity do not underlie deep muscle pain in the early stages of vitamin D deficiency.

\section{Vitamin D deficiency causes muscle hyperinnervation by unmyelinated CGRP-ir axons}

There is growing evidence that many clinical pain syndromes are accompanied by nociceptor axon sprouting within affected peripheral tissues (Bohm-Starke et al., 1999; Alfredson et al., 2003; Schubert et al., 2005). Because steroid hormones other than vitamin D can influence sensory axonal outgrowth (Blacklock et al., 2005), we examined skeletal muscle innervation in control and vitamin $\mathrm{D}$-deficient rats. Sections were immunostained for peripherin, a marker used to identify intact small-diameter unmyelinated axons (Goldstein et al., 1991). Peripherinimmunoreactive (-ir) nerve density was increased nearly twofold
Table 2. No changes in bone parameters were found in rats fed vitamin D-deficient diets for 4 weeks

\begin{tabular}{llllll}
\hline & Growth plate & & & Diaphysis & \\
\cline { 2 - 3 } \cline { 5 - 6 } & Thickness $(\mu \mathrm{m})$ & Cell \#/column & & Circumference $(\mathrm{mm})$ & Marrow area $\left(\mathrm{mm}^{2}\right)$ \\
\hline Control & $282 \pm 20$ & $20.8 \pm 0.9$ & & $6.9 \pm 0.1$ & $3.5 \pm 0.1$ \\
VD $-/+$ Ca & $274 \pm 25$ & $20.0 \pm 1.0$ & & $7.1 \pm 0.4$ & $3.6 \pm 0.3$ \\
VD- & $279 \pm 14$ & $21.1 \pm 1.0$ & & $6.8 \pm 0.4$ & $3.5 \pm 0.2$ \\
\hline
\end{tabular}

No significant differences were found. Values shown are mean \pm SEM.
A

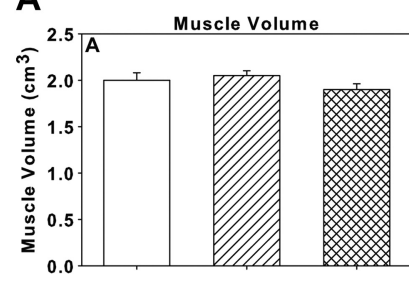

C

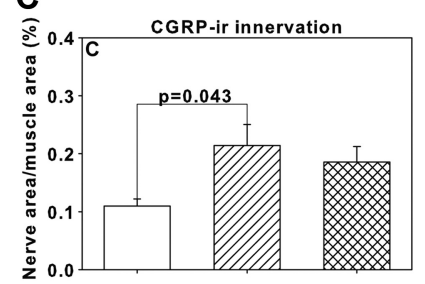

E

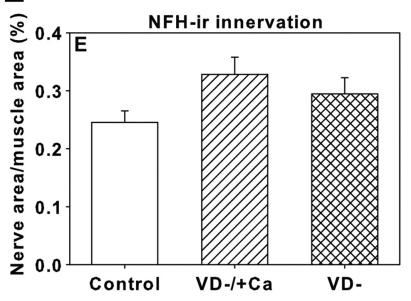

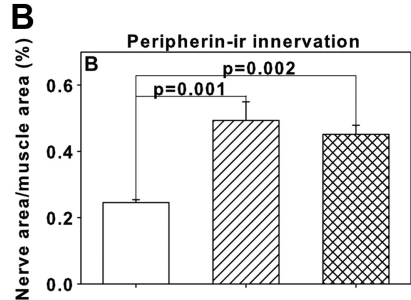

$\mathbf{D}$

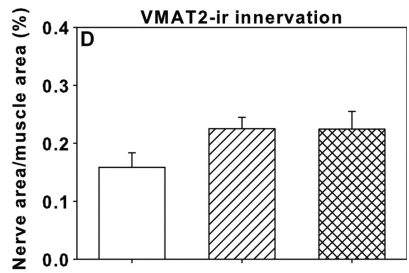

F

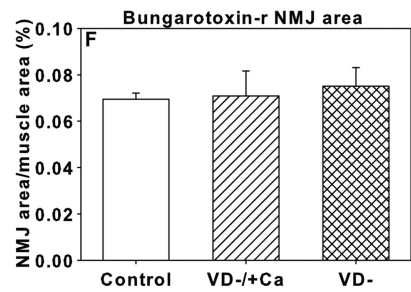

Figure 3. Comparisons of innervation densities of the lateral gastrocnemius muscles of rats after 4 weeks on control, VD- $+C a$, or VD - diets. $A$, There were no changes in the volumes of the calf muscles as measured by fluid displacement. $\boldsymbol{B}-\boldsymbol{E}$, There were significant increases in the percentage of nerve area per field area of peripherin-immunoreactive (ir) fibers ( $\boldsymbol{B}$ ) and CGRP-ir sensory peptidergic nerves $(\boldsymbol{C})$ in muscles from vitamin D-deficient rats, but not VMAT2-ir sympathetic $(\boldsymbol{D})$ or NFH-ir myelinated $(\boldsymbol{E})$ nerve fibers. $\boldsymbol{F}$, There were also no changes in neuromuscular junction (NMJ) area as measured by $\alpha$-bungarotoxin binding reactivity $(-r)$. 

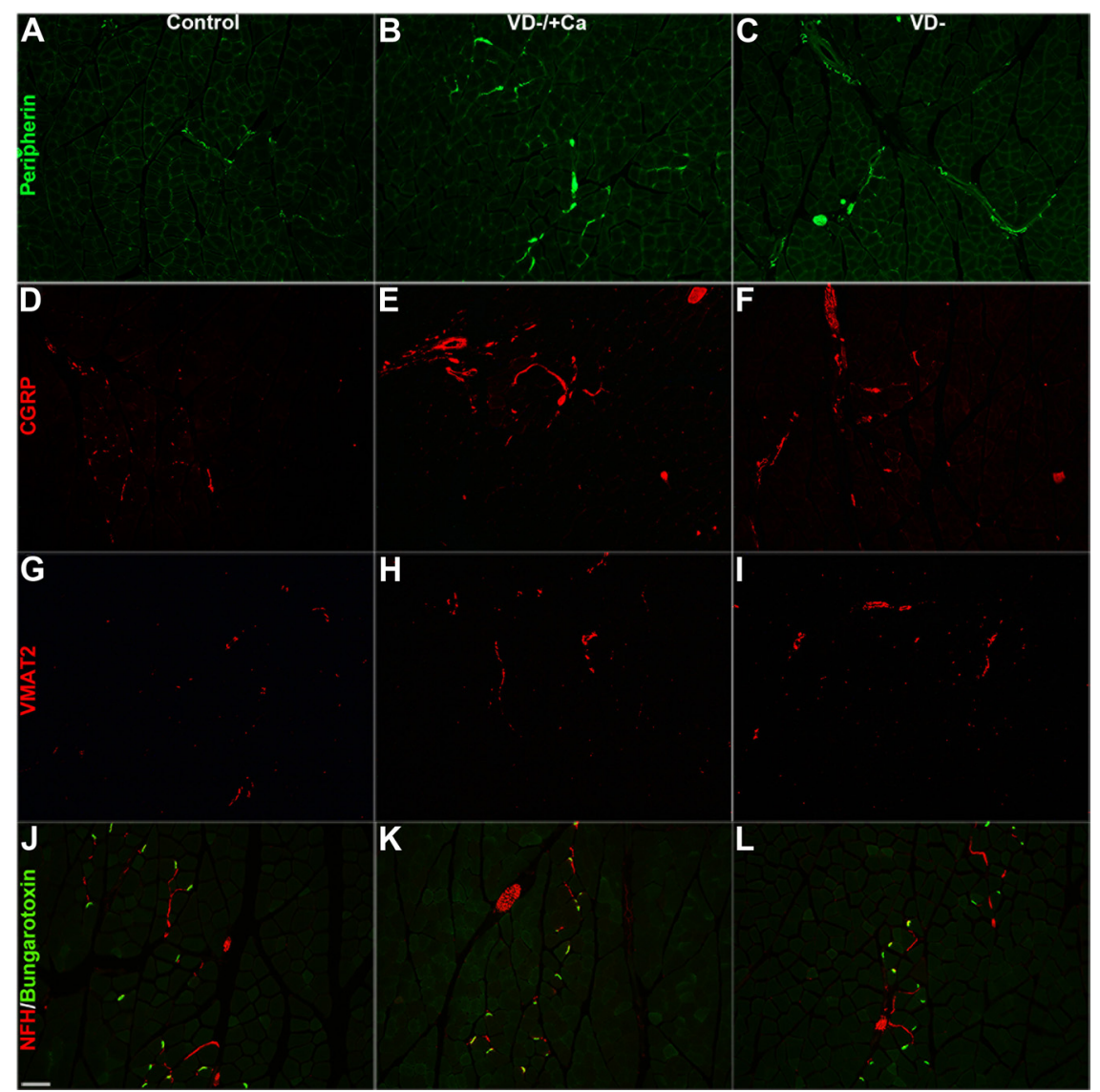

Figure 4. Immunoreactive nerves in gastrocnemius muscle. Transverse sections of the lateral gastrocnemius of rats receiving control $(\boldsymbol{A}, \boldsymbol{D}, \boldsymbol{G}, \boldsymbol{J}), \mathrm{VD}-\boldsymbol{I}+\mathrm{Ca}(\boldsymbol{B}, \boldsymbol{E}, \boldsymbol{H}, \boldsymbol{K})$, or VD - $(\boldsymbol{C}, \boldsymbol{F}, \boldsymbol{I}, \boldsymbol{L})$ diets were immunostained for peripherin $(\boldsymbol{A}-\boldsymbol{C}$, green), CGRP (D-F, red), $\operatorname{VMAT2}(\mathbf{G}-\mathbf{I}$, red), or NFH $(\boldsymbol{J}-\boldsymbol{L}$, red) and bungarotoxin (J-L, green). Scale bar (in $J), 50 \mu \mathrm{m}$ for all panels.

the dermal-epidermal junction using the pan-neuronal marker PGP 9.5 (Lauria et al., 2005) (Fig. 5A-C). Using this method, we found no significant differences in intra-epidermal nerve density (Fig. 5G). However, this method does not account for potential growth or branching of axons within the epidermis. We therefore also examined the total density of PGP 9.5-ir nerve fibers within the epidermis, but still found no significant differences between groups (Fig. 5I). Because PGP 9.5 is a pan-neuronal marker and the majority of nerve fibers in the epidermis are not sensory peptidergic nerve fibers, changes in peptidergic nerve fiber density could have been masked. We therefore also examined CGRP-ir epidermal nerve fibers (Fig. 5D-F), but still found no differences using either method of quantitation (Fig. $5 \mathrm{H}, \mathrm{J}$ ), suggesting that 4 weeks of a vitamin D-deficient diet does not lead to changes in epidermal innervation, which is consistent with the lack of observed changes in cutaneous sensitivity.

\section{Sensory growth cones are enriched in VDR protein}

Adult sensory DRG neurons in vivo contain receptors and metabolic enzymes for vitamin D (Tague and Smith, 2011). Accordingly, vitamin D deficiency could affect muscle innervation through a direct action on neurons. To test this hypothesis, adult DRG neurons were grown in vitro.

in $\mathrm{VD}-1+\mathrm{Ca}(p=0.001)$ and $\mathrm{VD}-(p=0.002)$ relative to control rats (Figs. $3 B, 4 A-C$ ). To identify which populations of fibers are increased in vitamin $\mathrm{D}$ deficiency, muscle sections were immunostained for CGRP as a marker for "peptidergic" nociceptors (Lawson, 1992), and VMAT2 for noradrenergic sympathetic axons (Headley et al., 2007). Approximately 90\% of all CGRP-ir neurons contained peripherin regardless of treatment (Control, $87 \pm 2 \%$; VD-/ Ca, $91 \pm 3 \%$; VD-, $93 \pm 5 \%)$. CGRP-ir axon density was increased approximately twofold (Figs. $3 C, 4 D-F ; p=$ 0.043 , VD-/Ca vs control), while that of VMAT2-ir was not significantly different (Figs. 3D, 4G-I). To determine whether myelinated fibers innervating the muscle are affected in vitamin D deficiency, muscle sections were immunostained for neurofilament $\mathrm{H}$ (NFH), a marker of large myelinated motor and proprioceptive fibers, and $\alpha$-bungarotoxin, which reveals terminal muscle innervation by staining motor end plates. We found no significant changes in sectional area of NFH-ir (Figs. $3 E, 4 J-L$ ) or bungarotoxin between control and vitamin D-deficient muscles. These findings indicate that vitamin $\mathrm{D}$ deficiency leads to selective muscle hyperinnervation by putative peptidergic nociceptors.

\section{Cutaneous innervation density is not altered by vitamin D deficiency}

To determine whether vitamin $\mathrm{D}$ deficiency also leads to hyperinnervation of cutaneous tissues, we examined epidermal innervation of hindpaw footpads. In humans, changes in intraepidermal nerve fiber density are most commonly measured in skin biopsies by counting the number of nerve fibers that cross
We first verified VDR expression in cultured neurons by immunostaining, and observed VDR-ir localized to the nucleus and somal cytoplasm (Fig. 6A, B). Interestingly, VDR appeared to be concentrated in growth cones of peripherin-ir neurites, where it extended distally into filopodia and showed spatial colocalization with the growth-associated protein GAP43 (Fig. 6C-E), suggesting a role for VDR in growth cone kinetics.

\section{$1,25(\mathrm{OH})_{2} \mathrm{D} 3$ modulates neurite outgrowth from putative nociceptor neurons}

To determine whether the VDRs might be playing a role in axonal sprouting, we measured neurite outgrowth from peripherin-ir DRG sensory neurons cultured with various concentrations of $1,25(\mathrm{OH})_{2} \mathrm{D} 3$. Normal mean serum concentration of $1,25(\mathrm{OH})_{2} \mathrm{D}$ is $\sim 80 \mathrm{pm}$ (Lund et al., 1979), whereas a study of patients with severe musculoskeletal pain reported 1,25dihydroxyvitamin D levels ranging from 12 to 45 pM (Gloth et al., 1991). To bracket this range, we added $1,25(\mathrm{OH})_{2} \mathrm{D} 3$ in concentrations between 0 and 100 pM to primary DRG cultures. Peripherin-ir DRG neurons grown with concentrations of $1,25(\mathrm{OH})_{2} \mathrm{D} 3$ between 60 and $100 \mathrm{pM}$, corresponding to normal serum levels, showed typical axon outgrowth (Fig. 6A). However, below 60 pM, there was an increase in neurite outgrowth, peaking at $20 \mathrm{pM}$, where outgrowth was $60 \%$ greater than controls ( 20 pM vs 0,60 , or $100 \mathrm{pM}, p<0.001$; $20 \mathrm{pM}$ vs 10 or $80 \mathrm{pM}, p=0.002 ; 20 \mathrm{pM}$ vs $40 \mathrm{pM}, p=0.011 ; 40 \mathrm{pM}$ vs $0 \mathrm{pm}, p=0.048$ ) (Fig. $6 G, I)$. These findings indicate that $1,25(\mathrm{OH})_{2} \mathrm{D} 3$ can directly affect sensory axon outgrowth from small fiber nerves. 
Vitamin D does not alter sympathetic neurite outgrowth

In vivo findings suggest that vitamin D's effects are restricted to unmyelinated sensory neurons. To confirm vitamin D's selectivity, we cultured superior cervical ganglion (SCG) sympathetic neurons. Immunostaining showed VDR-ir in SCG neuronal cytoplasmic and nuclear compartments (Fig. 7A-C). However, unlike sensory neurons, VDR-ir appeared to be uniform throughout sympathetic neurites and was not enriched in terminal axonal growth cones (Fig. 6C,E). Varying concentrations of $1,25(\mathrm{OH})_{2} \mathrm{D} 3$ also failed to affect sympathetic neurite outgrowth (Fig. 6F), consistent with observations that VMAT2-ir axon density did not change in vitamin D-deficient rats.

\section{VDR rapid response mechanisms regulate sensory neurite outgrowth}

VDRs can signal through either classical nuclear genomic binding sites or rapid response pathways via membrane-bound receptors that modulate ion flux and generation of second messengers (Mizwicki and Norman, 2009). The enrichment of VDR in growth cones of vitamin D-sensitive sensory axons, but not insensitive sympathetic axons, suggests that axon outgrowth may be regulated by nongenomic VDRs. To determine whether sensory axon outgrowth is regulated by rapid membrane signaling mechanisms, we used JN, which selectively binds to and activates membrane VDRs but has no effect on nuclear VDR signaling (Norman et al., 1997). JN was applied to DRG cultures in the same concentrations as $1,25(\mathrm{OH})_{2} \mathrm{D} 3$ in the previous experiment. Immunostaining for large-diameter $\mathrm{NFH}$-ir neurons, which primarily express only nuclear VDRs in vivo (Tague and Smith, 2011), showed no effect of JN on outgrowth, indicating that large-diameter neurons fail to respond to low levels of membrane VDR activation with increased outgrowth (Fig. 6J). However, JN did elicit neurite outgrowth of peripherin-ir fibers at low concentrations similar to those of $1,25(\mathrm{OH})_{2} \mathrm{D} 3$, with peak outgrowth occurring at $\sim 20 \mathrm{pM}$ (Fig. $6 \mathrm{~J}, 20 \mathrm{pM}$ vs $0,60,80$, or 100 pM, $p<0.001 ; 20$ pM vs 40 pM, $p=0.011 ; 10$ pM vs $60 \mathrm{pM}, p<0.001$, 10 pM vs 0,80 , or 100 pM, $p=0.001 ; 10$ pM vs $40 \mathrm{pm}, p=0.025)$. Therefore, low levels of rapid response VDR activation are most likely to enhance neurite outgrowth from putative nociceptors.

\section{Discussion}

Chronic musculoskeletal pain is a widespread and costly disorder for which clinical therapy is relatively ineffective (Stewart et al., 2003; De Inocencio, 2004; Bergman, 2007). Some types of musculoskeletal pain (e.g., fibromyalgia) likely occur independent of vitamin D status (de Rezende Pena et al., 2010; Heidari et al., 2010), but a substantial body of clinical data implicates vitamin D deficiency in nonspecific musculoskeletal pain (Gloth et al., 1991; Glerup and Eriksen, 1999; Plotnikoff and Quigley, 2003; Macfar- lane et al., 2005; Benson et al., 2006; de Torrenté de la Jara et al., 2006; Heidari et al., 2010; McBeth et al., 2010) and suggests that supplementation attenuates pain in some individuals (Gloth et al., 1991; Glerup and Eriksen, 1999; de Torrenté de la Jara et al., 2006; Heaney, 2008). Nonetheless, the role of vitamin D in musculoskeletal pain remains controversial in light of limitations inherent to human clinical studies.

Behavioral symptoms of early vitamin D deficiency, similar to those occurring in humans, are replicated in this rodent model, including deep muscle sensitivity and balance deficits. Protracted vitamin D deficiency results in major bone pathology, a proposed origin of musculoskeletal pain (Mascarenhas and Mobarhan, 2004). However, morphological analyses showed normal skeletal features after 4 weeks of a vitamin D-deficient diet, indicating that skeletal pathology is unlikely to contribute to muscle pain at this time. Moreover, simple muscle compression is unlikely to have exerted significant pressure on adjacent bone. While myopathic changes could also produce sensitivity, we found no evidence of muscle wasting or diminished muscle strength. Although our study was limited to the hindlimb musculature (the site most strongly linked to vitamin D-deficiency pain; Heidari et al., 2010), it is likely to apply to other muscles in which pain has been reported (Al Faraj and Al Mutairi, 2003; de Torrenté de la Jara et al., 2004; Lotfi et al., 2007; Heidari et al., 2010; McBeth et 

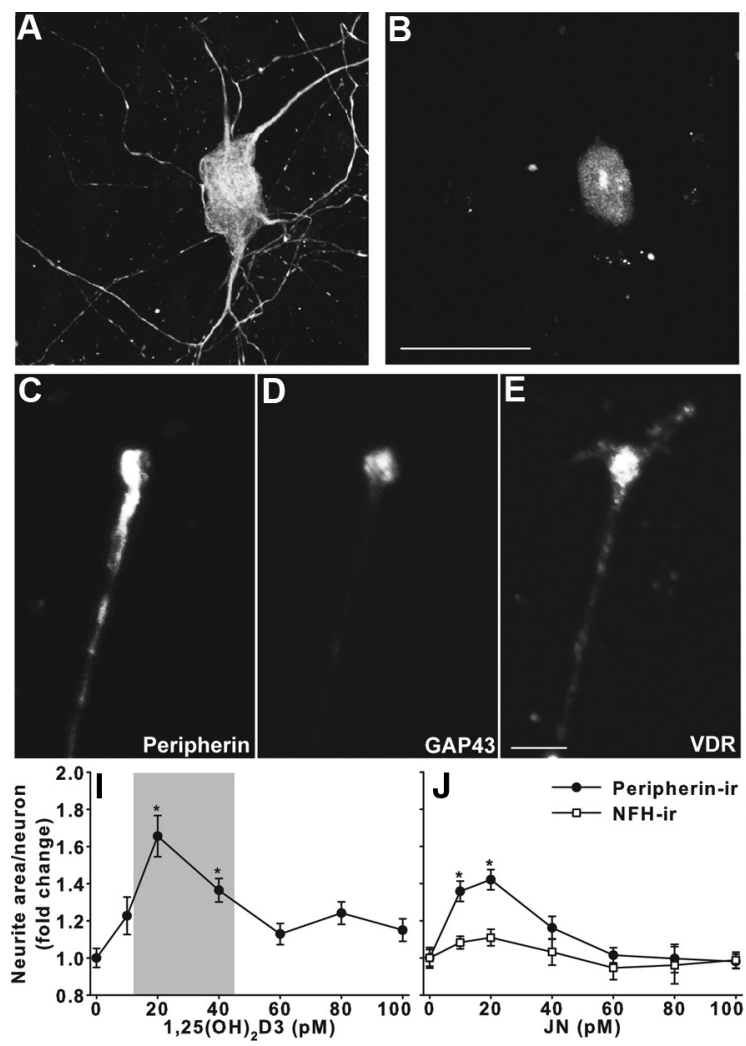

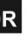
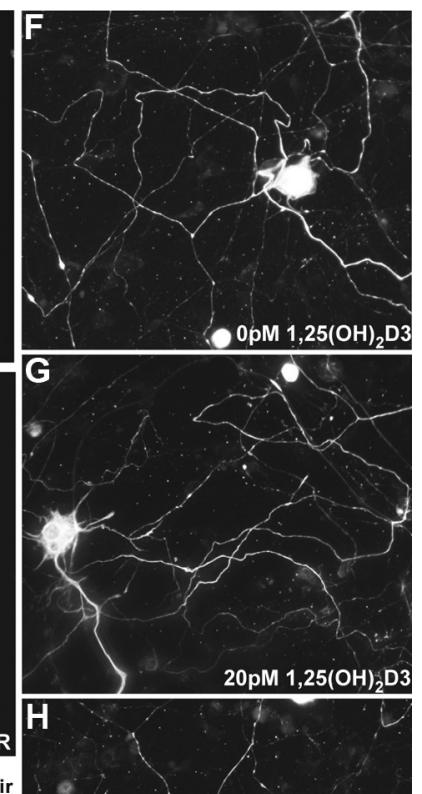

Figure 6. $\quad 1,25(\mathrm{OH})_{2} \mathrm{D} 3$ acts directly on peripherin-ir sensory nerves to regulate axonal growth. $\boldsymbol{A}, \boldsymbol{B}$, Primary DRG cultures immunostained for peripherin $(\boldsymbol{A})$ and vitamin $D$ receptors $(\boldsymbol{B}, \mathrm{VDR})$, showing that VDR is expressed by cultured sensory neurons and localized to both the nucleus and the cytoplasm in cultures without added 1,25(OH) 2 D3 (scale bar, $50 \mu \mathrm{m}$ ). $\mathbf{C}-\boldsymbol{E}$, At a higher magnification, peripherin-ir neurites ( $\boldsymbol{C}$ contain the growth cone marker GAP43 (D) localized to the axon tip, and this colocalizes with VDR $(\boldsymbol{E})$, which also extends into the filopodia. Scale bar (in $\boldsymbol{E}), 5 \mu \mathrm{m}$ for $\boldsymbol{C}-\boldsymbol{E}$. $\boldsymbol{F}-\boldsymbol{H}$, Representative images of neurons treated with $0(\boldsymbol{F}), 20(\boldsymbol{G})$, or $100 \mathrm{pm}(\boldsymbol{H})$ 1,25(0H) 2 D3. Scale bar (in $\boldsymbol{H}), 50 \mu \mathrm{m}$ for $\boldsymbol{F}$ - $\boldsymbol{H}$. I, Fold change in peripherin-ir neurite area per neuron at various $1,25(\mathrm{OH})_{2} \mathrm{D} 3$ concentrations. Results reveal a biphasic curve with the peak at $20 \mathrm{pm}$. The shaded area corresponds to $1,25(\mathrm{OH})_{2} \mathrm{D} 3$ levels reported in patients with severe pain (Gloth et al., 1991). J, DRG cultures treated with JN, a selective agonist for membrane/cytoplasm-localized rapid response VDRs, and stained for peripherin (O) or NFH ( $\square$ ). While there was no significant change in NFH-ir neurite area /neuron, there was a biphasic response to JN, with a peak at 20 pm in peripherin-ir axons. ${ }^{*} p<0.05$.

al., 2010). The observations presented here lend strong credence to the idea that mild or early vitamin D deficiency can result in skeletal muscle pain in the absence of gross musculoskeletal pathology.

Our findings support the idea that muscle pain in vitamin D deficiency is directly attributable to diminutions of this secosteroid. A problem in human studies is the difficulty presented by confounding variables such as light exposure, body mass, hormonal fluctuations, and serum calcium levels. By using ovariectomized rats, the impact of hormonal variations was minimized. Similarly, changes in body mass can reasonably be excluded as a participating factor. An important variable that could contribute to both hypersensitivity and disequilibrium is serum calcium levels, which can affect muscle and nerve function. Prolonged vitamin D deficiency induces hypocalcemia by interfering with calcium homeostasis. Hypocalcemia can be prevented by elevating dietary calcium and phosphorus (Weishaar and Simpson, 1987), and one subject group in our study received such a diet. However, serum measurements showed normal calcium and phosphorous levels, despite significantly lower serum $25(\mathrm{OH}) \mathrm{D}$ levels at 2-4 weeks in both vitamin D-deficient groups. This is consistent with reports of normal serum calcium levels in patients with vitamin D deficiency and musculoskeletal pain (Masood et al., 1989; Gloth et al., 1991).
It was intriguing, however, that a highcalcium diet actually accelerated the onset of muscle hypersensitivity relative to rats receiving vitamin D-deficient diet alone. Elevated dietary calcium in rats is reported to inhibit the $1 \alpha$-hydroxylase conversion of $25(\mathrm{OH}) \mathrm{D}$ to $1,25(\mathrm{OH})_{2} \mathrm{D}$ (Mallon et al., 1981; Anderson et al., 2010), which may have exacerbated effects of the vitamin D-deficient diet. Whatever the mechanism, this finding may be germane considering that $43 \%$ of the population uses calcium supplements (Bailey et al., 2010). Calcium supplements taken to promote bone health might actually exacerbate muscle pain in vitamin $\mathrm{D}$-deficient individuals.

Many factors may contribute to altered deep muscle sensitivity. While plasticity of central pathways may be the primary mediator of muscle pain in fibromyalgia (Bradley, 2009), local factors within the muscle itself are likely responsible for other types. Muscle pain is believed to derive from unmyelinated sensory fibers located within the surrounding fascia and discrete "pain spots" located deep within the muscle (Meadows, 1970). Our finding that the affected tissue shows selective hyperinnervation by putative nociceptors is in accord with reports describing hypersensitivity accompanied by abnormal increases in presumptive "pain-sensing" nerves (Bohm-Starke et al., 1999; Alfredson et al., 2003; Schubert et al., 2005). While the contribution of increased innervation to pain sensitivity remains unclear, actively growing axons show greater excitability than quiescent axons (Jänig et al., 2009), as do neurons with more complex axonal geometries (Janse et al., 1999). Similarly, more extensive axonal branching likely results in greater summation of locally evoked depolarizing potentials. Accordingly, the finding that low vitamin D levels induce sprouting from putative nociceptors is consistent with increased muscular sensitivity to mechanical stimulation.

Another factor that could contribute to increased sensitivity is muscle inflammation. Vitamin D has anti-inflammatory properties (Skyba et al., 2005; Baeke et al., 2010), so deficiency of this hormone could make tissues more susceptible to inflammation. However, histological analysis of muscle sections showed no evidence of immune cell infiltration in vitamin D-deficient rats, suggesting that muscle inflammation is not the primary cause of muscle hypersensitivity. Nonetheless, hyperinnervation by CGRP-ir axons may increase the propensity for neurogenic inflammation within muscle. Antidromic activation of peptidergic c-fibers results in release of CGRP and tachykinins, which promote vasodilation, protein extravasation, mast cell degranulation, and infiltration and activation of immune cells (Maggi, 1995). This can further increase CGRP and tachykinin production (Ambalavanar et al., 2006), resulting in the release of cytokines, growth factors, and other 

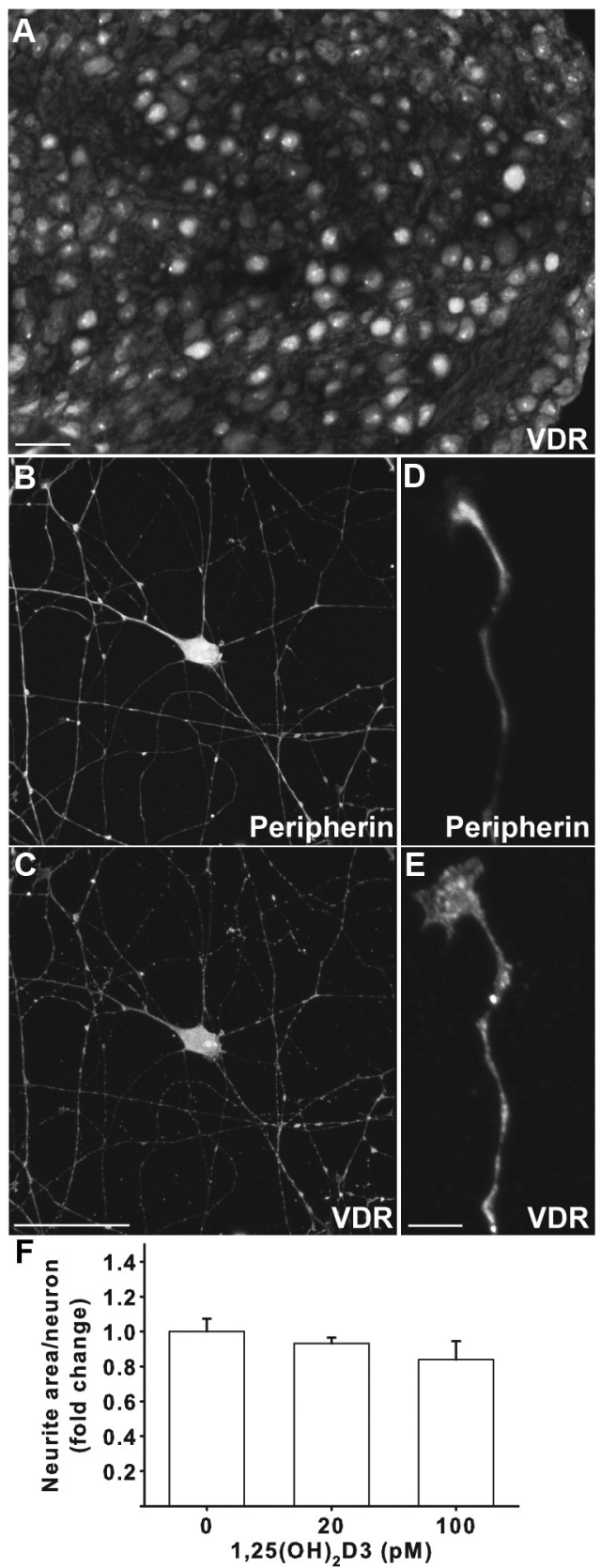

Figure 7. Sympathetic neurons express VDRs, but $1,25(\mathrm{OH})_{2} \mathrm{D} 3$ has no effect on neurite outgrowth. $A$, Sympathetic neurons of SCGs were immunofluorescently labeled for VDR. VDR was localized to the nucleus and cytoplasm of selected neurons. $\boldsymbol{B}-\boldsymbol{E}$, Primary SCG cultures immunofluorescently stained for peripherin $(\boldsymbol{B}, \boldsymbol{D})$ and $\operatorname{VDR}(\boldsymbol{C}, \boldsymbol{E})$. Scale bars: (in $\boldsymbol{B}) \boldsymbol{B}, \boldsymbol{C}, 50 \mu \mathrm{m}$; (in $\boldsymbol{D}) \boldsymbol{D}, \boldsymbol{E}, 5 \mu \mathrm{m}$. VDR was localized throughout the cell body $(\boldsymbol{C})$, neurite $(\boldsymbol{C}, \boldsymbol{E})$, and growth

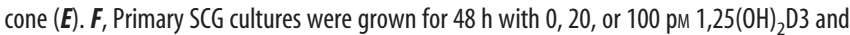
immunofluorescently labeled with peripherin. There were no significant changes in neurite area/neuron.

substances by the tissue, which can sensitize nociceptor terminals (Richardson and Vasko, 2002). Accordingly, while inflammation may not be a requirement for vitamin D-deficient skeletal muscle hypersensitivity and hyperinnervation, increased nociceptor fiber density could contribute to the establishment of chronic muscle pain through neurogenic inflammatory mechanisms.

The impaired beam walk performance in our rodent model is consistent with observations that falls are more frequent in vitamin D-deficient humans (Annweiler et al., 2010). However, the mechanism remains uncertain. While bone or muscle pathology could contribute, we failed to detect histopathological changes. Indices of motor activity and muscle strength were also normal, similar to findings that vitamin D-deficient humans have normal grip strength and gait speed (Faulkner et al., 2006). Another possibility is that vitamin D deficiency leads to proprioceptive deficits; however, myelinated axons, which include proprioceptors, do not appear to be altered in vitamin $\mathrm{D}$ deficiency. Certainly other aspects of peripheral or central proprioceptive pathways could well be affected. Alternatively, in light of the muscle hypersensitivity and hyperinnervation occurring in these animals, an equally plausible explanation is that muscle pain evoked during movement impairs the ability to make fine motor corrections, leading to increased balance beam foot faults.

An interesting feature of vitamin D deficiency-induced nociceptor hyperinnervation and hypersensitivity is its tissue selectivity; skeletal muscle showed both nociceptor hyperinnervation and hypersensitivity, but hindpaw skin showed neither. Subphysiological levels of $1,25(\mathrm{OH})_{2} \mathrm{D}$ promote nociceptor neuron sprouting in vitro in the absence of target, indicating that vitamin $\mathrm{D}$ induces sprouting by acting directly on the neuron. However, other factors likely account for tissue selectivity. For example, all nociceptor populations may be affected, but some targets provide an environment permissive to sprouting (muscle) while others do not (skin). Similarly, local tissue concentrations of $1,25(\mathrm{OH})_{2} \mathrm{D}$ may vary. Alternatively, perhaps only subpopulations of nociceptor neurons, such as those projecting to skeletal muscle, respond to reduced $1,25(\mathrm{OH})_{2} \mathrm{D}$ by sprouting. Additional studies are needed to fully assess the mechanism of this specificity.

In neurons responding to hypovitaminosis $\mathrm{D}$, there are several mechanisms by which $1,25(\mathrm{OH})_{2} \mathrm{D}$ levels may affect axon outgrowth. Rapid response VDRs are known to regulate PKC, MAPK, PLC, PLA, Src, and Raf activation, $\mathrm{Ca}^{2+}$ and $\mathrm{Cl}^{-}$channel opening, and sphingomyelin hydrolysis (Mizwicki and Norman, 2009). Any of these downstream mediators could regulate axon growth.

This study used ovariectomized rats, partially because women with reduced ovarian hormones (i.e., postmenopausal or estrogen-suppressed) are particularly susceptible to developing vitamin D deficiency and musculoskeletal pain (Gaugris et al., 2005; Alexander et al., 2007; Khan et al., 2010). In addition, it was thought that the reduction in VDR expression in sensory nerves following ovariectomy might enhance the effects of vitamin D deficiency (Tague and Smith, 2011). However, there are correlative data from clinical studies showing that men also develop hypovitaminosis D-induced musculoskeletal pain (McBeth et al., 2010). Accordingly, these findings may have wider applicability to normally cycling females and males as well.

Vitamin D has been touted as an alternative therapy for musculoskeletal pain. Our findings provide a biological basis for advocating dietary supplementation to achieve euvitaminosis D in musculoskeletal pain patients. The controlled experimental conditions directly implicate serum vitamin D deficiency in the etiology of deep muscle pain. Given that vitamin $\mathrm{D}$ supplementation is safe, inexpensive, and has few side effects (Heaney, 2008), our findings suggest that it may be a useful prophylactic for muscle pain. 


\section{References}

Alexander JL, Dennerstein L, Woods NF, Halbreich U, Kotz K, Richardson G, Graziottin A, Sherman JJ (2007) Arthralgias, bodily aches and pains and somatic complaints in midlife women: etiology, pathophysiology and differential diagnosis. Expert Rev Neurother 7:S15-S26.

Al Faraj S, Al Mutairi K (2003) Vitamin D deficiency and chronic low back pain in Saudi Arabia. Spine 28:177-179.

Alfredson H, Ohberg L, Forsgren S (2003) Is vasculo-neural ingrowth the cause of pain in chronic Achilles tendinosis? An investigation using ultrasonography and colour Doppler, immunohistochemistry, and diagnostic injections. Knee Surg Sports Traumatol Arthrosc 11:334-338.

Ambalavanar R, Moritani M, Moutanni A, Gangula P, Yallampalli C, Dessem D (2006) Deep tissue inflammation upregulates neuropeptides and evokes nociceptive behaviors which are modulated by a neuropeptide antagonist. Pain 120:53-68.

Anderson PH, Lee AM, Anderson SM, Sawyer RK, O'Loughlin PD, Morris HA (2010) The effect of dietary calcium on 1,25(OH)2D3 synthesis and sparing of serum 25(OH)D3 levels. J Steroid Biochem Mol Biol 121:288-292.

Annweiler C, Montero-Odasso M, Schott AM, Berrut G, Fantino B, Beauchet O (2010) Fall prevention and vitamin D in the elderly: an overview of the key role of the non-bone effects. J Neuroeng Rehabil 7:50.

Baeke F, Gysemans C, Korf H, Mathieu C (2010) Vitamin D insufficiency: implications for the immune system. Pediatr Nephrol 25:1597-1606.

Bailey RL, Dodd KW, Goldman JA, Gahche JJ, Dwyer JT, Moshfegh AJ, Sempos CT, Picciano MF (2010) Estimation of total usual calcium and vitamin D intakes in the United States. J Nutr 140:817-822.

Benson J, Wilson A, Stocks N, Moulding N (2006) Muscle pain as an indicator of vitamin D deficiency in an urban Australian Aboriginal population. Med J Aust 185:76-77.

Bergman S (2007) Public health perspective- how to improve the musculoskeletal health of the population. Best Pract Res Clin Rheumatol 21:191-204.

Besalduch N, Santafé MM, Garcia N, Gonzalez C, Tomás M, Tomás J, Lanuza MA (2011) Transmitter release in the neuromuscular synapse of the protein kinase C theta-deficient adult mouse. J Comp Neurol 519:849-855.

Blacklock AD, Johnson MS, Krizsan-Agbas D, Smith PG (2005) Estrogen increases sensory nociceptor neuritogenesis in vitro by a direct, nerve growth factor-independent mechanism. Eur J Neurosci 21:2320-2328.

Bohm-Starke N, Hilliges M, Falconer C, Rylander E (1999) Neurochemical characterization of the vestibular nerves in women with vulvar vestibulitis syndrome. Gynecol Obstet Invest 48:270-275.

Bradley LA (2009) Pathophysiology of fibromyalgia. Am J Med 122 [Suppl]:S22-S30.

Chakrabarty A, Blacklock A, Svojanovsky S, Smith PG (2008) Estrogen elicits dorsal root ganglion axon sprouting via a renin-angiotensin system. Endocrinology 149:3452-3460.

Chakrabarty A, McCarson KE, Smith PG (2011) Hypersensitivity and hyperinnervation of the rat hind paw following carrageenan-induced inflammation. Neurosci Lett 495:67-71.

Christianson JA, Ryals JM, Johnson MS, Dobrowsky RT, Wright DE (2007) Neurotrophic modulation of myelinated cutaneous innervation and mechanical sensory loss in diabetic mice. Neuroscience 145:303-313.

Clarke GL, Bhattacherjee A, Tague SE, Hasan W, Smith PG (2010) Betaadrenoceptor blockers increase cardiac sympathetic innervation by inhibiting autoreceptor suppression of axon growth. J Neurosci 30:12446-12454.

Craft RM (2007) Modulation of pain by estrogens. Pain 132 [Suppl 1]:S3-S12.

De Inocencio J (2004) Epidemiology of musculoskeletal pain in primary care. Arch Dis Child 89:431-434.

de Rezende Pena C, Grillo LP, das Chagas Medeiros MM (2010) Evaluation of 25-hydroxyvitamin $\mathrm{d}$ serum levels in patients with fibromyalgia. J Clin Rheumatol 16:365-369.

de Torrenté de la Jara G, Pécoud A, Favrat B (2004) Musculoskeletal pain in female asylum seekers and hypovitaminosis D3. BMJ 329:156-157.

de Torrenté de la Jara G, Pécoud A, Favrat B (2006) Female asylum seekers with musculoskeletal pain: the importance of diagnosis and treatment of hypovitaminosis D. BMC Fam Pract 7:4.

Demay MB (2006) Mechanism of vitamin D receptor action. Ann N Y Acad Sci 1068:204-213.
Faulkner KA, Cauley JA, Zmuda JM, Landsittel DP, Newman AB, Studenski SA, Redfern MS, Ensrud KE, Fink HA, Lane NE, Nevitt MC (2006) Higher 1,25-dihydroxyvitamin D3 concentrations associated with lower fall rates in older community-dwelling women. Osteoporos Int 17:1318-1328.

Fowler SC, Birkestrand BR, Chen R, Moss SJ, Vorontsova E, Wang G, Zarcone TJ (2001) A force-plate actometer for quantitating rodent behaviors: illustrative data on locomotion, rotation, spatial patterning, stereotypies, and tremor. J Neurosci Methods 107:107-124.

Gaugris S, Heaney RP, Boonen S, Kurth H, Bentkover JD, Sen SS (2005) Vitamin D inadequacy among post-menopausal women: a systematic review. QJM 98:667-676

Glerup H, Eriksen EF (1999) Acroparaesthesia—a typical finding in vitamin D deficiency. Rheumatology (Oxford) 38:482.

Gloth FM 3rd, Lindsay JM, Zelesnick LB, Greenough WB 3rd (1991) Can vitamin D deficiency produce an unusual pain syndrome? Arch Intern Med 151:1662-1664.

Goldstein ME, House SB, Gainer H (1991) NF-L and peripherin immunoreactivities define distinct classes of rat sensory ganglion cells. J Neurosci Res 30:92-104.

Headley DB, Suhan NM, Horn JP (2007) Different subcellular distributions of the vesicular monoamine transporter, VMAT2, in subclasses of sympathetic neurons. Brain Res 1129:156-160.

Heaney RP (2008) Vitamin D: criteria for safety and efficacy. Nutr Rev 66 [Suppl 2]:S178-S181.

Heidari B, Shirvani JS, Firouzjahi A, Heidari P, Hajian-Tilaki KO (2010) Association between nonspecific skeletal pain and vitamin D deficiency. Int J Rheum Dis 13:340-346.

Herde MK, Friauf E, Rust MB (2010) Developmental expression of the actin depolymerizing factor $\mathrm{ADF}$ in the mouse inner ear and spiral ganglia. J Comp Neurol 518:1724-1741.

Jänig W, Grossmann L, Gorodetskaya N (2009) Mechano- and thermosensitivity of regenerating cutaneous afferent nerve fibers. Exp Brain Res 196:101-114.

Janse C, Peretz B, van der Roest M, Dubelaar EJ (1999) Excitability and branching of neuroendocrine cells during reproductive senescence. Neurobiol Aging 20:675-683.

Khan QJ, Reddy PS, Kimler BF, Sharma P, Baxa SE, O’Dea AP, Klemp JR, Fabian CJ (2010) Effect of vitamin D supplementation on serum 25hydroxy vitamin D levels, joint pain, and fatigue in women starting adjuvant letrozole treatment for breast cancer. Breast Cancer Res Treat 119:111-118.

Lauria G, Cornblath DR, Johansson O, McArthur JC, Mellgren SI, Nolano M, Rosenberg N, Sommer C (2005) EFNS guidelines on the use of skin biopsy in the diagnosis of peripheral neuropathy. Eur J Neurol 12:747-758.

Lawson SN (1992) Morphological and biochemical cell types of sensory neurons. In: Sensory neurons: diversity, development, and plasticity (Scott SA, ed), pp 27-59. New York: Oxford UP.

Lester GE, VanderWiel CJ, Gray TK, Talmage RV (1982) Vitamin D deficiency in rats with normal serum calcium concentrations. Proc Natl Acad Sci U S A 79:4791-4794

Lotfi A, Abdel-Nasser AM, Hamdy A, Omran AA, El-Rehany MA (2007) Hypovitaminosis D in female patients with chronic low back pain. Clin Rheumatol 26:1895-1901.

Lund B, Lund B, Sørensen OH (1979) Measurement of circulating 1,25dihydroxyvitamin $\mathrm{D}$ in man. Changes in serum concentrations during treatment with 1 alpha-hydroxycholecalciferol. Acta Endocrinol (Copenh) 91:338-350.

Macfarlane GJ, Palmer B, Roy D, Afzal C, Silman AJ, O’Neill T (2005) An excess of widespread pain among South Asians: are low levels of vitamin D implicated? Ann Rheum Dis 64:1217-1219.

Maggi CA (1995) Tachykinins and calcitonin gene-related peptide (CGRP) as co-transmitters released from peripheral endings of sensory nerves. Prog Neurobiol 45:1-98.

Mallon JP, Boris A, Bryce GF (1981) Decrease in serum levels of 1,25dihydroxycholecalciferol in rats and chickens fed a vitamin D-deficient diet. J Nutr 111:665-667.

Mascarenhas R, Mobarhan S (2004) Hypovitaminosis D-induced pain. Nutr Rev 62:354-359.

Masood H, Narang AP, Bhat IA, Shah GN (1989) Persistent limb pain and 
raised serum alkaline phosphatase the earliest markers of subclinical hypovitaminosis D in Kashmir. Indian J Physiol Pharmacol 33:259-261.

McBeth J, Pye SR, O’Neill TW, Macfarlane GJ, Tajar A, Bartfai G, Boonen S, Bouillon R, Casanueva F, Finn JD, Forti G, Giwercman A, Han TS, Huhtaniemi IT, Kula K, Lean ME, Pendleton N, Punab M, Silman AJ, Vanderschueren D, et al. (2010) Musculoskeletal pain is associated with very low levels of vitamin D in men: results from the European Male Ageing Study. Ann Rheum Dis 69:1448-1452.

Meadows JC (1970) Observations on muscle pain in man, with particular reference to pain during needle electromyography. J Neurol Neurosurg Psychiatry 33:519-523.

Mizwicki MT, Norman AW (2009) The vitamin D sterol-vitamin D receptor ensemble model offers unique insights into both genomic and rapidresponse signaling. Sci Signal 2:re4.

Muller KA, Ryals JM, Feldman EL, Wright DE (2008) Abnormal muscle spindle innervation and large-fiber neuropathy in diabetic mice. Diabetes 57:1693-1701.

Norman AW, Okamura WH, Hammond MW, Bishop JE, Dormanen MC, Bouillon R, van Baelen H, Ridall AL, Daane E, Khoury R, Farach-Carson MC (1997) Comparison of 6-s-cis- and 6-s-trans-locked analogs of 1alpha,25-dihydroxyvitamin D3 indicates that the 6-s-cis conformation is preferred for rapid nongenomic biological responses and that neither 6-s-cis- nor 6-s-trans-locked analogs are preferred for genomic biological responses. Mol Endocrinol 11:1518-1531.

Plotnikoff GA, Quigley JM (2003) Prevalence of severe hypovitaminosis D in patients with persistent, nonspecific musculoskeletal pain. Mayo Clin Proc 78:1463-1470.

Richardson JD, Vasko MR (2002) Cellular mechanisms of neurogenic inflammation. J Pharmacol Exp Ther 302:839-845.

Ruscheweyh R, Forsthuber L, Schoffnegger D, Sandkühler J (2007) Modification of classical neurochemical markers in identified primary afferent neurons with Abeta-, Adelta-, and C-fibers after chronic constriction injury in mice. J Comp Neurol 502:325-336.
Schott GD, Wills MR (1976) Muscle weakness in osteomalacia. Lancet $1: 626-629$.

Schubert TE, Weidler C, Lerch K, Hofstädter F, Straub RH (2005) Achilles tendinosis is associated with sprouting of substance $\mathrm{P}$ positive nerve fibres. Ann Rheum Dis 64:1083-1086.

Sharma NK, Ryals JM, Liu H, Liu W, Wright DE (2009) Acidic salineinduced primary and secondary mechanical hyperalgesia in mice. J Pain 10:1231-1241.

Skyba DA, Radhakrishnan R, Sluka KA (2005) Characterization of a method for measuring primary hyperalgesia of deep somatic tissue. J Pain 6:41-47.

Smittkamp SE, Spalding HN, Brown JW, Gupte AA, Chen J, Nishimune H, Geiger PC, Stanford JA (2010) Measures of bulbar and spinal motor function, muscle innervation, and mitochondrial function in ALS rats. Behav Brain Res 211:48-57.

Stewart WF, Ricci JA, Chee E, Morganstein D, Lipton R (2003) Lost productive time and cost due to common pain conditions in the US workforce. JAMA 290:2443-2454.

Tague SE, Smith PG (2011) Vitamin D receptor and enzyme expression in dorsal root ganglia of adult female rats: modulation by ovarian hormones. J Chem Neuroanat 41:1-12.

Watanabe Y, Inoue K, Okuyama-Yamamoto A, Nakai N, Nakatani J, Nibu K, Sato N, Iiboshi Y, Yusa K, Kondoh G, Takeda J, Terashima T, Takumi T (2009) Fezf1 is required for penetration of the basal lamina by olfactory axons to promote olfactory development. J Comp Neurol 515:565-584.

Weishaar RE, Simpson RU (1987) Vitamin D3 and cardiovascular function in rats. J Clin Invest 79:1706-1712.

Witkovsky P, Veisenberger E, Haycock JW, Akopian A, Garcia-Espana A, Meller E (2004) Activity-dependent phosphorylation of tyrosine hydroxylase in dopaminergic neurons of the rat retina. J Neurosci 24:4242-4249.

Yetley EA (2008) Assessing the vitamin D status of the US population. Am J Clin Nutr 88:558S-564S. 